\title{
Characterization of Plasma Lipoproteins in Survivors of Cerebral Infarction
}

\author{
Atsushi Murai, ${ }^{*}$ Tadao Miyahara, Tomoji Tanaka and \\ Masakuni Kameyama \\ Department of Geriatrics, Kyoto University Hospital, \\ Sakyoku, Kyoto 606
}

\begin{abstract}
Murai, A., Miyahara, T., Tanaka, T. and Kameyama, M. Characterization of Plasma Lipoproteins in Survivors of Cerebral Infarction. Tohoku J. exp. Med., 1986, 148 (1), 57-64_To characterize the plasma lipoproteins in survivors of cerebral infarction, plasma lipoproteins were ultracentrifugally fractionated into VLDL, LDL, $\mathrm{HDL}_{2}$ and $\mathrm{HDL}_{3}$, and the concentrations of cholesterol, phospholipid, apolipoprotein and triglyceride in each lipoprotein class were determined. Subjects examined were 15 male healthy controls and 15 male survivors of cerebral infarction situated in the distribution of cerebral cortical artery. The concentrations of VLDL-cholesterol and VLDL-triglyceride and the percent content of VLDL-cholesterol were higher in survivors than in controls. The concentration of LDL-triglyceride was higher and the percent content of LDL-cholesterol was lower in survivors than in controls. While the plasma concentration of triglyceride was higher in survivors than in controls, those of $\mathrm{HDL}, \mathrm{HDL}_{2}$ and $\mathrm{HDL}_{3}$ were lower in survivors. The concentrations of cholesterol, phospholipid and apolipoprotein in either $\mathrm{HDL}_{2}$ or $\mathrm{HDL}_{3}$ were also reduced in survivors as compared with controls. In either $\mathrm{HDL}_{2}$ or $\mathrm{HDL}_{3}$, the percent content of triglyceride was higher and that of phospholipid was lower in survivors than in controls. These results were in good agreement with those reported for survivors of myocardial infarction, suggesting that the underlying derangement in lipoprotein metabolism is common to myocardial and cerebral infarction. cerebral infarction; atherosclerosis ; plasma lipoprotein; high density lipoprotein subfraction; chemical composition
\end{abstract}

It has long been observed that elevated plasma concentrations of total cholesterol, low density lipoprotein (LDL) and very low density lipoprotein (VLDL) play an important role in the development of coronary heart disease (Kannel et al. 1971; Carlson 1982). In recent years, attention has been focused on the association of reduced concentrations of high density lipoprotein (HDL) cholesterol and coronary heart disease (Miller and Miller 1975). In addition, antiatherogenic action is believed to be much more potent in an HDL subfraction,

Received May 25, 1985; accepted for publication November 22, 1985.

*To whom reprint requests should be sent.

Abbreviations used are: VLDL, very low density lipoprotein; LDL, low density lipoprotein; HDL, high density lipoprotein; EDTA, ethylenediaminetetraacetate; SDS, sodium dodecylsulfate 
$\mathrm{HDL}_{2}$, rather than in whole HDL (Gofman et al. 1966; Hammett et al. 1979). These results are supported by several prospective studies conducted in different countries (Gofman et al. 1966 ; Gordon et al. 1977 ; Enger et al. 1979 ; Goldbourt and Medalie 1979).

Characterization of each plasma lipoprotein class-chemical composition as well as plasma levels-in atherosclerotic vascular disease is considered essential for elucidating the pathogenesis of atherosclerosis. Avogaro et al. (1979) studied abnormalities in plasma concentrations and chemical compositions of major lipoproteins characteristic of survivors of myocardial infarction. Although atherosclerotic arterial lesions are considered responsible for the development of infarction in the distribution of the cerebral cortical artery as well as of the coronary artery (Murai et al. 1981), little has been published so far about the plasma lipoprotein profile in cerebral infarction (Rössner et al. 1978; Murai et al. 1982).

In the present study, it was undertaken to disclose plasma concentrations and chemical compositions of lipoproteins in survivors of cerebral infarction.

\section{Subjects And Methods}

The subjects examined were 15 male healthy controls from the medical staff and 15 male survivors of cerebral infarction for whom at least two months had elapsed after the onset of infarction. Any survivors complicated by ischemic heart disease were excluded. All members of the infarction group had suffered from infarction situated in the distribution of, not the cerebral perforating arteries, but the cerebral cortical arteries of which atherosclerotic arterial lesions might be underlying the infarction (Murai et al. 1981). The diagnosis of cerebral infarction was made from the subject's history, clinical signs and symptoms and the findings of computerizd cerebral axial tomography. The profiles of these subjects are shown in Table 1.

Venous blood was collected from the subjects who had fasted overnight. Plasma lipoproteins were ultracentrifugally fractionated in a Hitachi RP 65TA rotor (Hitachi, Ltd., Tokyo) at $10^{\circ} \mathrm{C}$ at $105,000 \times \mathrm{g}$ according to the method of Havel (Havel et al. 1955). A floating fraction was collected with a tube slicer and the density of infranate was raised with the addition of $\mathrm{d}=1.35 \mathrm{~g} / \mathrm{ml} \mathrm{NaCl}-\mathrm{NaBr}$ solution containing $0.05 \% \mathrm{EDTA}, \mathrm{pH} 7.1$, followed by further ultracentrifugation. VLDL, $\mathrm{LDL}, \mathrm{HDL}_{2}$ and $\mathrm{HDL}_{3}$ were collected as a fraction floating in ultracentrifugation at $\mathrm{d}=1.006 \mathrm{~g} / \mathrm{ml}$ for $16 \mathrm{hr}$, at $\mathrm{d}=1.063 \mathrm{~g} / \mathrm{ml}$ for $24 \mathrm{hr}$, at $\mathrm{d}=$ $1.125 \mathrm{~g} / \mathrm{ml}$ for $36 \mathrm{hr}$ and at $\mathrm{d}=1.21 \mathrm{~g} / \mathrm{ml}$ for $36 \mathrm{hr}$, respectively. Both $\mathrm{HDL}_{2}$ and $\mathrm{HDL}_{3}$ fractions were dialyzed against $0.15 \mathrm{M} \mathrm{NaCl}$ containing $0.05 \%$ EDTA, pH 7.1, before chemical analysis.

Total cholesterol, phospholipid and triglyceride concentrations of plasma and each lipoprotein fraction were determined by an enzymatic method (TC-Kit, Nippon Shoji,

Table 1. Profile of the subjects examined

\begin{tabular}{lccc}
\hline & $\begin{array}{c}\text { Number of } \\
\text { cases }\end{array}$ & Age (year) & $\begin{array}{c}\text { Relative weight } \\
(\%)\end{array}$ \\
\hline Survivors of cerebral infarction & 15 & $\begin{array}{c}60.9 \pm 12.9 \\
(34-73)\end{array}$ & $104.8 \pm 7.3$ \\
Healthy controls & 15 & $\begin{array}{c}31.3 \pm 6.5 \\
(25-48)\end{array}$ & $95.3 \pm 8.0$ \\
\hline
\end{tabular}


TABle 2. Plasma lipid concentrations in survivors of cerebral infarction and in controls

\begin{tabular}{lcc}
\hline & $\begin{array}{c}\text { Survivors } \\
(\mathrm{mg} / 100 \mathrm{ml})\end{array}$ & $\begin{array}{c}\text { Controls } \\
(\mathrm{mg} / 100 \mathrm{ml})\end{array}$ \\
\hline Total cholesterol & $202.5 \pm 70.9$ & $182.1 \pm 31.1$ \\
Phospholipid & $220.0 \pm 48.6$ & $214.8 \pm 40.1$ \\
Triglyceride & $163.1 \pm 80.2^{*}$ & $90.1 \pm 30.5$ \\
\hline
\end{tabular}

* $p<0.01$ Mean \pm s.D.

TABLE 3. Plasma concentrations of major lipoprotein fractions and their components in survivors of cerebral infarction and in controls

\begin{tabular}{|c|c|c|c|c|c|}
\hline & $\begin{array}{l}\text { Cholesterol } \\
(\mathrm{mg} / 100 \mathrm{ml})\end{array}$ & $\begin{array}{l}\text { Phospholipid } \\
(\mathrm{mg} / 100 \mathrm{ml})\end{array}$ & $\begin{array}{l}\text { Apoprotein } \\
(\mathrm{mg} / 100 \mathrm{ml})\end{array}$ & $\begin{array}{l}\text { Triglyceride } \\
(\mathrm{mg} / 100 \mathrm{ml})\end{array}$ & $\begin{array}{c}\text { Total } \\
(\mathrm{mg} / 100 \mathrm{ml})\end{array}$ \\
\hline \multicolumn{6}{|l|}{ Survivors } \\
\hline VLDL & $22.9 \pm 13.8^{*}$ & $36.1 \pm 21.3$ & $30.9 \pm 13.6$ & $101.5 \pm 55.9^{*}$ & $191.3 \pm 102.4$ \\
\hline LDL & $139.2 \pm 79.5$ & $91.3 \pm 48.5$ & $124.1 \pm 47.0$ & $43.0 \pm 12.9 \dagger$ & $397.6 \pm 181.4$ \\
\hline $\mathrm{HDL}_{2}$ & $14.4 \pm 6.3 \dagger$ & $21.4 \pm 8.6 \dagger$ & $35.9 \pm 12.8^{*}$ & $5.7 \pm 2.8$ & $77.4 \pm 29.3 \dagger$ \\
\hline $\mathrm{HDL}_{3}$ & $24.6 \pm 5.5 \ddagger$ & $45.2 \pm 10.1 \ddagger$ & $109.3 \pm 31.3 \dagger$ & $8.4 \pm 3.4$ & $187.6 \pm 45.8 \dagger$ \\
\hline \multicolumn{6}{|l|}{ Controls } \\
\hline VLDL & $10.2 \pm 9.5$ & $34.2 \pm 46.3$ & $21.4 \pm 20.3$ & $51.7 \pm 43.0$ & $117.5 \pm 102.6$ \\
\hline LDL & $115.7 \pm 33.3$ & $74.9 \pm 22.5$ & $97.2 \pm 29.3$ & $28.4 \pm 7.8$ & $316.2 \pm 90.7$ \\
\hline $\mathrm{HDL}_{2}$ & $21.6 \pm 6.8$ & $34.3 \pm 13.2$ & $50.0 \pm 15.4$ & $5.0 \pm 1.9$ & $111.0 \pm 35.4$ \\
\hline $\mathrm{HDL}_{3}$ & $33.3 \pm 5.4$ & $61.3 \pm 13.1$ & $136.6 \pm 21.1$ & $8.6 \pm 9.4$ & $239.7 \pm 35.8$ \\
\hline
\end{tabular}

Osaka), by a digestion method with sulfuric acid and manganese dioxide (PhospholipidTest, Wako Pure Chemical Industries, Ltd., Osaka) and by an acetyl acetone method (Triglyceride-Test, Wako Pure Chemical Industries, Ltd.), respectively. Apolipoprotein concentrations were determined by Lowry's method using bovine serum albumin as a standard (Lowry et al. 1951). Ultracentrifugally separated lipoproteins, particularly $\mathrm{HDL}_{2}$ and $\mathrm{HDL}_{3}$, were usually contaminated with albumin. Hence, either $\mathrm{HDL}_{2}$ or $\mathrm{HDL}_{3}$ was delipidated and electrophoresed on an SDS-glycerol polyacrylamide gel (Connelly and Kuksis 1982). Gels were stained with Coomassie Brilliant Blue and subjected to a densitometry. As albumin was completely separated from apolipoproteins, the proportion of albumin and apolipoproteins could be determined, allowing calculation of the corrected contents of apolipoprotein in $\mathrm{HDL}_{2}$ and $\mathrm{HDL}_{3}$. Plasma concentrations of each lipoprotein fraction were obtained as a sum of four components : cholesterol, phospholipid, apolipoprotein and triglyceride.

\section{RESUlts}

\section{Plasma lipid}

Plasma concentrations of total cholesterol, phospholipid and triglyceride in survivors of cerebral infarction and in controls are shown in Table 2. Plasma 
concentrations of total cholesterol and phospholipid were higher in survivors than in controls. However, these differences did not reach a statistical significance. On the contrary, plasma triglyceride concentrations in survivors were significantly higher than in controls.

Very low density lipoprotein (VLDL)

Although the concentration of VLDL and its components-VLDLcholesterol, VLDL-phospholipid, VLDL-apolipoprotein and VLDL-triglyceride - were higher in survivors than in controls (Table 3), the differences reached a statistical significance only in the concentrations of VLDL-cholesterol and triglyceride. The chemical composition of VLDL is shown in Table 4 in which percent content of cholesterol was significantly higher in survivors than in controls. Thus, the survivors of cerebral infarction were considered to carry cholesterol-rich VLDL.

\section{Low density lipoprotein (LDL)}

No significant differences between survivors and controls were found in the plasma concentrations of LDL and its components except for LDL-triglyceride (Table 3). The percent content of cholesterol was significantly lower in survivors than in controls, whereas the percent content of apolipoprotein was rather higher in survivors, resulting in a lower cholesterol to apolipoprotein ratio of LDL in survivors $(1.08 \pm 0.17)$ than that in controls $(1.20 \pm 0.13)$ (Teng et al. 1983), although not statistically significant. The percent content of either phospholipid or triglyceride did not differ between survivors and controls (Table 4).

TABLE 4. Chemical composition of major lipoprotein fractions in survivors of cerebral infarction and in controls

\begin{tabular}{ccccc}
\hline & $\begin{array}{c}\text { Cholesterol } \\
(\%)\end{array}$ & $\begin{array}{c}\text { Phospholipid } \\
(\%)\end{array}$ & $\begin{array}{c}\text { Apoprotein } \\
(\%)\end{array}$ & $\begin{array}{c}\text { Triglyceride } \\
(\%)\end{array}$ \\
\hline $\begin{array}{c}\text { Survivors } \\
\text { VLDL }\end{array}$ & $11.8 \pm 1.7 \ddagger$ & $18.5 \pm 2.5$ & $17.3 \pm 5.5$ & $52.5 \pm 5.5$ \\
LDL & $34.1 \pm 3.7^{*}$ & $22.5 \pm 1.7$ & $31.8 \pm 2.6$ & $11.6 \pm 3.9$ \\
$\mathrm{HDL}_{3}$ & $18.6 \pm 2.6$ & $27.2 \pm 3.2 \dagger$ & $47.0 \pm 2.8$ & $7.2 \pm 1.9 \ddagger$ \\
$\mathrm{HDL}_{3}$ & $12.9 \pm 1.4 \dagger$ & $23.7 \pm 1.9^{*}$ & $58.9 \pm 2.2$ & $4.5 \pm 1.7 \ddagger$ \\
Controls & & & & \\
VLDL & $8.9 \pm 1.5$ & $23.2 \pm 13.3$ & $21.2 \pm 11.8$ & $46.7 \pm 10.7$ \\
$\mathrm{LDL}$ & $36.6 \pm 1.7$ & $23.6 \pm 0.9$ & $30.6 \pm 2.1$ & $9.1 \pm 1.2$ \\
$\mathrm{HDL}$ & $19.7 \pm 3.0$ & $30.4 \pm 3.0$ & $45.4 \pm 3.5$ & $4.6 \pm 1.0$ \\
$\mathrm{HDL}_{3}$ & $14.1 \pm 0.9$ & $25.7 \pm 2.2$ & $57.6 \pm 2.0$ & $2.6 \pm 0.8$ \\
\hline
\end{tabular}

Chemical compositions were calculated by dividing each component concentration by total concentration.

* $p<0.05, \quad \dagger p<0.01, \quad \ddagger p<0.001$.

Mean \pm S.D. 


\section{High density lipoprotein (HDL)}

The plasma concentrations of $\mathrm{HDL}, \mathrm{HDL}_{2}$ and $\mathrm{HDL}_{3}$ were significantly lower in survivors than in controls (Table 3). In addition, $\mathrm{HDL}_{2}$ to $\mathrm{HDL}_{3}$ ratio was lower in survivors than in controls, indicating that the reduction of $\mathrm{HDL}_{2}$ concentration exceeded that of $\mathrm{HDL}_{3}$ concentration. The plasma concentrations of cholesterol, phospholipid and apolipoprotein in either $\mathrm{HDL}_{2}$ or $\mathrm{HDL}_{3}$ were significantly lower in survivors than in controls. However, no significant difference was found between the plasma concentrations of triglyceride of the two subject groups in either $\mathrm{HDL}_{2}$ or $\mathrm{HDL}_{3}$ (Table 3).

The percent contents of phospholipid in survivors were significantly lower than in controls in both $\mathrm{HDL}$ subfractions, $\mathrm{HDL}_{2}$ and $\mathrm{HDL}_{3}$. Similarly, the percent content of cholesterol in the former group was significantly lower than that in the latter group in $\mathrm{HDL}_{3}$ alone. On the other hand, the percent content of triglyceride in survivors was significantly higher than in controls in either $\mathrm{HDL}_{2}$ or $\mathrm{HDL}_{3}$ (Table 4).

\section{Discussion}

Two lipoprotein classes are known to be atherogenic: one is cholesterol-rich $\beta$-VLDL and the other is LDL. The present study indicated that at least some survivors of cerebral infarction were carrying cholesterol-rich VLDL. On the other hand, LDL, a major cholesterol transporting lipoprotein, is considered not to be homogeneous. Sniderman et al. (1980) claimed that the plasma concentration of LDL apolipoprotein (apo B) may frequently be increased in patients with coronary heart disease despite their having an LDL cholesterol within the normal range and this abnormality is pronounced in not heavy but light LDL particles (Sniderman et al. 1980; Teng et al. 1983). It was shown by these investigators that cholesterol to apolipoprotein $\mathrm{B}$ ratio in coronary heart disease is significantly lower than that in control when light subfraction of LDL was examined (Teng et al. 1983). Hence, it seems important that in survivors of cerebral infarction situated in the distribution of cortical artery of the brain, the percent content of cholesterol was found to be significantly lower than in controls and the cholesterol to apolipoprotein ratio was found to be lower than in controls, although LDL had not been further fractionated. The precise mechanism by which the compostional abnormalities of VLDL, LDL, $\mathrm{HDL}_{2}$ and $\mathrm{HDL}_{3}$ were brought about is unclear. However, if plasma lipoprotein metabolism is retarded, transfer or exchange reactions may progress excessively between lipoproteins; cholesterol ester is transferred from LDL or HDL to VLDL while triglyceride is transferred from VLDL to LDL or HDL (Morton and Zilversmit.1983; Chait et al. 1984). These metabolic abnormalities may contribute to the development of atherosclerosis as well.

Changes in plasma concentrations and chemical compositions of major lipo- 
protein classes characteristic of survivors of myocardial infarction were recently studied (Avogaro et al. 1979). Most lipoprotein abnormalities reported in their study were observed in the present study in which plasma lipoproteins were investigated in survivors of cerebral infarction; the concentrations of both HDL subfractions, $\mathrm{HDL}_{2}$ and $\mathrm{HDL}_{3}$, were significantly lower in survivors of cerebral infarction than in controls. The concentrations of cholesterol, apolipoprotein and phospholipid contained in either the $\mathrm{HDL}_{2}$ or $\mathrm{HDL}_{3}$ subfraction were also significantly reduced in survivors as compared with controls. In either $\mathrm{HDL}_{2}$ or $\mathrm{HDL}_{3}$, the percent content of triglyceride was significantly higher and that of phospholipid was significantly lower in survivors than in controls. Thus almost identical results were found for plasma concentrations and chemical compositions of either $\mathrm{HDL}_{2}$ or $\mathrm{HDL}_{3}$ subfractions. These findings strongly suggest that the underlying derangement in lipoprotein metabolism is common to myocardial and cerebral infarctions which are situated in the distribution of, not the perforating artery, but the cortical artery of the brain.

The concentrations of either $\mathrm{HDL}_{2}$ or $\mathrm{HDL}_{3}$ were shown to be reduced in cerebral infarction as well as in myocardial infarction. In addition, the mean percent content of phospholipid in both $\mathrm{HDL}_{2}$ and $\mathrm{HDL}_{3}$ was also significantly lower in survivors of cerebral infarction than in controls whereas the mean percent content of triglyceride was significantly higher in survivors than in controls, indicating that the mean particle size was larger in cerebral infarction because phospholipid is a surface component of lipoprotein particle and triglyceride is a core component. It is widely accepted that the liver and intestine secrete HDL as disc-shaped precursor particles which mature in turn during circulation within the plasma and the interstitial space (Nestel and Fidge 1981). Moreover, recent evidence has shown that during lipolysis of triglyceride rich lipoprotein, bilayered lamellar structures are directly formed from redundant surface folds of lipoprotein particles, grow as cellular cholesterol and HDL apolipoprotein are transferred, and finally become a mature HDL particle (Tall and Small 1978; Nestel and Fidge 1981). Hence, it is suggested that the mean particle size of either $\mathrm{HDL}_{2}$ or $\mathrm{HDL}_{3}$ was larger in cerebral infarction than in controls due in part to the diminished formation of nascent HDL or bilayered lamellar structure of small size. In a previous study we showed that the percent content of phospholipid was significantly increased when the reduced concentrations of HDL were increased by pantethine administration to patients with cerebral infarction (Murai et al. 1983). Therefore, the possibility may be raised that the reduced concentration of HDL accompanied by the reduced percent content of phospholipid may reflect disturbances of HDL metabolism which accelerate the development of atherosclerosis of the cerebral arteries as well as of the coronary arteries.

\section{References}

1) Avogaro, P., Cazzolato, G., Bittolo Bon, G. \& Belussi, F. (1979) Levels and chemical 
composition of $\mathrm{HDL}_{2}, \mathrm{HDL}_{3}$ and other major lipoprotein classes in survivors of myocardial infarction. Artery, 5, 495-508.

2) Carlson, L.A. (1982) Serum lipids and atherosclerotic diseases. In : Metabolic Risk Factors in Ischemic Cardiovascular Disease, edited by L.A. Carlson \& B. Pernow, Raven Press, New York, pp. 1-16.

3) Chait, A., Eisenberg, S., Steinmetz, A., Albers, J.J. \& Bierman, E.L. (1984) Lowdensity lipoproteins modified by lipid transfer protein have altered biological activity. Biochim. biophys. Acta, 795, 314-325.

4) Connelly, P.W. \& Kuksis, A. (1982) SDS-glycerol polyacrylamide gel electrophoresis of plasma apolipoproteins. Biochim. biophys. Acta, 711, 245-251.

5) Enger, S.C., Hjermann, I., Foss, O.P., Helgeland, A., Holme, I., Leren, P. \& Norum, K. R. (1979) High density lipoprotein cholesterol and myocardial infarction or sudden coronary death: a prospective case-control study in middle-aged men of the Oslo study. Artery, 5, 170-181.

6) Gofman, J.W., Young, W. \& Tandy, R. (1966) Ischemic heart disease, atherosclerosis, and longevity. Circulation, 34, 679-697.

7) Goldbourt, U. \& Medalie, J.H. (1979) High density lipoprotein cholesterol and incidence of coronary heart disease-the Israeli ischemic heart disease study. Amer. J. Epidem., 109, 296-308.

8) Gordon, R., Castelli, W.P., Hjortland, M.C., Kannel, W.B. \& Dawber, T.R. (1977) High density lipoprotein as a protective factor against coronary heart disease. The Framingham study. Amer. J. Med., 62, 707-714.

9) Hammett, F., Saltissi, S., Miller, N., Rao, S., Van-Zeller, H., Coltart, J. \& Lewis, B. (1979) Relationship of coronary atherosclerosis to plasma lipoproteins. Circulation, 60, 11-167.

10) Havel, R.J., Eder, H.A. \& Bragdon, J.H. (1955) The distribution and chemical composition of ultracentrifugally separated lipoproteins in human serum. J. clin. Invest., 34, 1345-1353.

11) Kannel, W.B., Castelli, W.P., Gordon, T. \& McNamara, P.M. (1971) Serum cholesterol, lipoproteins, and the risk of coronary heart disease. The Framingham study. Ann. intern. Med., 74, 1-12.

12) Lowry, O.H., Rosebrough, N.J., Farr, A.L. \& Randall, R.J. (1951) Protein measurement with the Folin phenol reagent. J. biol. Chem., 193, 265-275.

13) Miller, G.J. \& Miller, N.E. (1975) Plasma-high-density-lipoprotein and development of ischemic heart disease. Lancet, 1, 16-19.

14) Morton, R.E. \& Zilversmit, D.B. (1983) Inter-relationship of lipids transferred by the lipid-transfer protein isolated from human lipoprotein-deficient plasma. J. biol. Chem., 258, 11751-11757.

15) Murai, A., Tanaka, T., Miyahara, T. \& Kameyama, M. (1981) Lipoprotein abnormalities in the pathogenesis of cerebral infarction and transient ischemic attack. Stroke, 12, $167-172$.

16) Murai, A., Miyahara, T., Tanaka, T. \& Kameyama, M. (1982) A simple method for quantitative determination of high density lipoprotein 2- and 3-cholesterol concentrations by means of polyacrylamide gel electrophoresis. Tohoku J.exp. Med., 137, 429435 .

17) Murai, A., Miyahara, T., Tanaka, T. \& Kameyama, M. (1983) The effects of pantethine on the lipoprotein abnormalities in cerebral infarction. Artery, 12, 234-243.

18) Nestel, P.J. \& Fidge, N.H. (1981) The physiology of plasma lipoproteins. In: Lipoproteins, Atherosclerosis and Coronary Heart Disease, edited by N.E. Miller \& B. Lewis, Elsevier/North-Holland, Amsterdam, pp. 3-29.

19) Rössner, S., Kjellin, K.G., Mettinger, K.L., Siden, A. \& Söderström, C.E. (1978) Normal serum-cholesterol but low H.D.L.-cholesterol concentration in young patients with ischemic cerebrovascular disease. Lancet, 1, 557-559. 
20) Sniderman, A., Shapiro, S., Marpole, D., Skinner, B., Teng, B. \& Kwiterovich, P.O., Jr. (1980) Association of coronary atherosclerosis with hyperapobetalipoproteinemia, increased protein but normal cholesterol levels in human plasma low density $(\beta)$ lipoproteins. Proc. nat. Acad. Sci., 77, 604-608.

21) Tall, A.R. \& Small, D.M. (1978) Plasma high-density lipoproteins. New Engl. J. Med., 299, 1232-1236.

22) Teng, B., Thompson, G.R., Sniderman, A.D., Forte, T.M., Krauss, R.M. \& Kwiterovich, P.O., Jr. (1983) Composition and distribution of low density lipoprotein fractions in hyperapobetalipoproteinemia, normolipidemia, and familial hypercholesterolemia. Proc. nat. Acad. Sci., 80, 6662-6666. 